\title{
Mechanosensing and fibrosis
}

\author{
Daniel J. Tschumperlin, ${ }^{1}$ Giovanni Ligresti, ${ }^{1}$ Moira B. Hilscher, ${ }^{2}$ and Vijay H. Shah' \\ 'Department of Physiology and Biomedical Engineering and 'Division of Castroenterology and Hepatology, Mayo Clinic, Rochester, Minnesota, USA.
}

\begin{abstract}
Tissue injury disrupts the mechanical homeostasis that underlies normal tissue architecture and function. The failure to resolve injury and restore homeostasis gives rise to progressive fibrosis that is accompanied by persistent alterations in the mechanical environment as a consequence of pathological matrix deposition and stiffening. This Review focuses on our rapidly growing understanding of the molecular mechanisms linking the altered mechanical environment in injury, repair, and fibrosis to cellular activation. In particular, our focus is on the mechanisms by which cells transduce mechanical signals, leading to transcriptional and epigenetic responses that underlie both transient and persistent alterations in cell state that contribute to fibrosis. Translation of these mechanobiological insights may enable new approaches to promote tissue repair and arrest or reverse fibrotic tissue remodeling.
\end{abstract}

Physical forces regulate molecular, cellular, and organ function, with well-recognized roles in mechanosensing, development, stem cell fate, and cancer (1-3). In the realm of tissue injury and repair, physical forces and their corresponding cellular responses play pivotal roles in the processes that initiate and resolve injury. Mechanical forces can conversely propagate pathological tissue remodeling and fibrosis in the context of failed repair or recurrent injury. Prominent examples of cellular force responses include cell-cell- and cell-matrix-mediated mechanoregulation of barrier function and activation of endothelial and epithelial cells in response to stretch and shear, as well as fibroblast responses to the rigidity and stretch of the extracellular matrix (ECM). This Review summarizes the roles the physical environment plays in tissue injury, repair, and fibrosis with a focus on the emerging details of molecular mechanosensing mechanisms as well as the potential for therapeutic targeting of mechanobiological aspects of fibrosis. We focus predominantly on the lung and liver as examples of organs where injury and fibrosis are intimately linked to mechanical forces and cellular mechanosensing.

\section{The physical environment in injury, repair, and fibrosis}

Tissue injuries of widely varying origins, including chemical, mechanical, or microbiological, initiate the processes that ultimately result in fibrosis. No matter the source, tissue injury inevitably disrupts the mechanical homeostasis that underlies normal tissue architecture and function (ref. 4 and Figure 1). While the initiation of injury may therefore be nonmechanical in nature, the physical effects are often profound. For example, chemical injury to the liver or lung generates necrotic and apoptotic death in tissue-residing cells, leading to release of acute injury signals and recruitment of innate immune cells $(5,6)$, which themselves experience mechanical signals during tissue recruitment (7). These processes alter

Conflict of interest: V.H. Shah is a consultant for Novartis. D.J. Tschumperlin reports research funding from Medlmmune.

Reference information: / Clin Invest. 2018;128(1):74-84.

https://doi.org/10.1172/JCI93561. local vascular permeability, promoting the leakage of circulating fluid-phase components and further cellular recruitment. Inflammatory signals and cytokines released in the setting of injury, such as TGF- $\beta$ and TNF- $\alpha$, prompt cytoskeletal remodeling that alters cell-generated forces and cellular mechanical properties (8-10). Interstitial fluid accumulation, amplified by deposition of woundassociated glycosaminoglycans such as hyaluronic acid, further distends the interstitial matrix (11). The nonlinear and strain-stiffening properties of biological materials translate tissue swelling and distention into a shift to a higher stiffness regime, without the need for new matrix deposition $(12,13)$. Hyaluronic acid and other matrix components provide a mechanically advantageous environment for cell activation (14). Gradients in mechanical properties within tissue may augment recruitment of cells through a process termed durotaxis (15). Thus, acute injury responses are inextricably linked to physical cellular and tissue-level changes, likely accounting for the early changes in tissue stiffness that are often observed prior to the de novo deposition of ECM (16).

The transition from a reparative to a fibrotic response likely arises from a failure or inability to resolve and repair injury. While multiple explanations for this transition have been offered (17, 18), mechanical forces are likely instrumental. For instance, while changes in vascular permeability evolved to mitigate acute injuries and initiate protective and reparative processes, failure to resolve such acute responses in a timely fashion imposes persistent aberrant mechanical states that play important roles in propagating injury and pathological remodeling $(4,19)$. Similarly, in dermal wound healing, tissue repair ultimately decreases stresses in the wound bed, allowing activated myofibroblasts to undergo apoptosis or return to a more quiescent state $(20,21)$. In contrast, wound splinting, which prevents dermal contraction, or exposure to chronic mechanical stresses maintains myofibroblast activation, impedes healing, and enhances scar formation. Shielding the wound from stress with load-reducing bandages improves healing $(22,23)$. While tissue-specific differences in skin and solidorgan wound healing exist, it is notable that myofibroblasts in the liver also revert to a more quiescent state during the resolution of fibrotic liver scarring (24). Such resolution processes promote the 


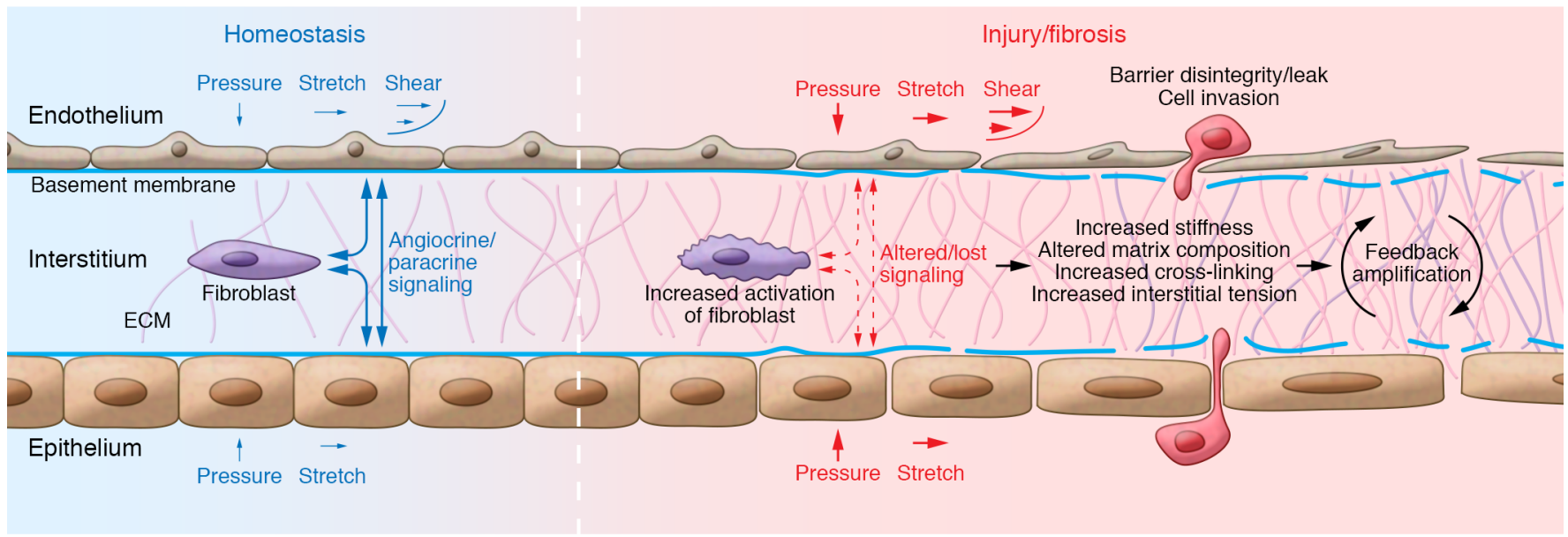

Figure 1. Physical and matrix changes in injury and fibrosis. This schematic shows a prototypical interstitial ECM compartment bounded by endothelial and epithelial barriers. At homeostasis, reciprocal interactions between these compartments maintain tissue integrity and function. Injury alters mechanical homeostasis via barrier compromise (endothelial and epithelial disintegrity), cell invasion, cell-generated forces, elevated externally applied stretch, shear, and pressure, as well as ECM deposition, compositional changes, and interstitial pressure changes. While transient perturbations of mechanical homeostasis promote fibroblast functions essential to normal wound healing, impaired healing or failure to resolve injury can lead to a persistently altered mechanical environment. In the absence of restoration of normal homeostatic mechanical and intercellular interactions, matrix stiffening promotes persistent cellular dysfunction and activation, leading to ongoing cycles of matrix deposition and stiffening.

normalization of tissue mechanical properties and restoration of homeostasis. While the liver has regenerative capacities to restore both architecture and mechanical properties even after progression to a fibrotic state (5), the extent to which fibrosis remains truly reversible in other organs remains controversial (25).

The ECM provides mechanical context for fibrotic remodeling. Whatever the causes of failed resolution, the mechanical environment in fibrotic scar tissue progresses inexorably toward a profoundly altered state characterized by increased tissue stiffness (26). This fibrotic, stiff matrix is also functionally implicated in promoting fibroblast activation, potentially generating feedback loops that propagate ECM deposition and fibrotic tissue remodeling (27). The dramatic increases in tissue stiffness are linked to fibrillar collagen deposition and cross-linking (26), with evidence from decellularized human lungs suggesting only modest direct mechanical contributions from cellular constituents (28). Notably, mimicking the physical and biochemical tissue environment present in mature fibrosis by culturing cells on decellularized matrices recapitulates cellular phenotypes in the fibrotic lung, suggesting that context plays a prominent role in defining cellular phenotypes in adherent cells $(29,30)$. Thus, the matrix likely contributes to the sustained cellular activation that promotes disease progression through both biochemical and mechanical signals (31). While reductionist two-dimensional hydrogel models have been instrumental in illuminating stiffness-dependent cell activation, tissue ECM is inherently more complex, and more sophisticated models, including those that incorporate true 3D geometry $(32,33)$, are likely to provide additional insights. Despite the growing appreciation of the mechanical signals provided by the ECM, major questions remain regarding the evolution of the matrix's mechanical milieu, particularly during the transition from normal injury repair to fibrosis, and the extent to which such changes are reversible along this continuum (34).
Targeting ECM to prevent and reverse fibrotic remodeling. Despite uncertainty about the potential to resolve established scar tissue, multiple efforts to target the matrix have been pursued. Uterine fibroid tissue, characterized by abundant fibrillar collagens, has shown impressive mechanical responsiveness to injection of a purified bacterial collagenase (35). While this approach is potentially useful for focal and accessible fibrotic tissues, it may be difficult to apply to organs with diffuse scarring. The lysyl oxidase (LOX) family of enzymes plays important roles in collagen cross-linking, contributing to both the mechanical properties and degradation resistance of collagen-rich matrices. Preclinical models reveal an impressive reduction in tissue stiffness and fibrosis with use of the nonspecific LOX inhibitor $\beta$-aminopropionitrile (BAPN) (36, 37). Strategies to target LOXL2, a family member more selectively expressed in pathological contexts, show promise in preclinical fibrosis models (37-39), but have so far proven disappointing in clinical trials (40). Beyond LOX family members, transglutaminase and nonenzymatic cross-linking via glycation may also contribute to collagen stabilization and matrix stiffening $(41,42)$.

While matrix-targeting concepts show some promise, these approaches face important barriers. They will likely require targeted delivery or selective activity on constituents and processes that are specific to pathological matrix remodeling in order to avoid deleterious effects on unaffected organs and tissue regions. Moreover, while the effort to arrest or reverse fibrotic matrix deposition is a worthy goal in itself, true tissue repair requires not only arrest of fibrosis, but also restoration of a functional and homeostatic ECM in the place of fibrotic scar. In pursuit of this goal, attention to the programs that control cellular deposition of ECM appears warranted. Combining the methods of ECM proteomics (43) with in vivo and in vitro methods to study cell-associated (44) and disease-associated matrices (45) may provide tools to elucidate how cells alter ECM composition, signaling function, and mechanical 


\section{Table 1. Mechanosensory molecules and pathways potentially active in fibrosis}

\begin{tabular}{|c|c|c|}
\hline $\begin{array}{l}\text { Molecules implicated in } \\
\text { mechanotransduction }\end{array}$ & $\begin{array}{l}\text { Potential interventions or } \\
\text { pharmacological tools }\end{array}$ & Key references \\
\hline \multicolumn{3}{|l|}{ Primary mechanosensors } \\
\hline$\alpha_{v}$ integrin & CWHM 12 & 96 \\
\hline$\alpha_{v} \beta_{1}$ integrin & Compound 8 & 95,98 \\
\hline$\alpha_{v} \beta_{3}$ integrin & Cilengitide & 197 \\
\hline$\alpha_{v} \beta_{6}$ integrin & BG00011 (STX-100) & 92,94 \\
\hline$\alpha_{6}$ integrin & & 79 \\
\hline VEGFR2/VEGFR3 & Tivozanib & 108 \\
\hline Notch & $\lambda$-Secretase inhibitors & $60,115,116$ \\
\hline FAK & PF-00562271, VS-4718 & 198, 199 \\
\hline Rho/ROCK & Fasudil, Y27632 & 132 \\
\hline \multicolumn{3}{|c|}{ Mechanosensitive ion channels } \\
\hline $\mathrm{PIEZO1/2}$ & Gadolinium, GsMTx4 & 51,52 \\
\hline TRPV4 & $\begin{array}{c}\text { GSK2193874, GSK1016790A, } \\
\text { RN-1734 }\end{array}$ & 200 \\
\hline TRPC6 & Larixyl acetate, BTP2 & 201,202 \\
\hline TRPC3 & Pyr3 & 203 \\
\hline \multicolumn{3}{|c|}{ Mechanosensitive transcription/epigenetic factors } \\
\hline KLF2 & Statins, resveratrol & 56,204 \\
\hline YAP/TAZ & Verteporfin & $126-128$ \\
\hline MRTF (MKL) & CCС-222740, ССС-203971 & $137,139,141,142$ \\
\hline miR-21 & miR-21 antagomir & 191 \\
\hline
\end{tabular}

environments. Similarly, the study of in vivo models that feature both tissue fibrosis and resolution may help identify cellular programs that drive both fibrotic scarring and regenerative healing. Much remains to be learned about how the mechanical environment evolves across the spectrum of injury, fibrosis, and tissue repair. But armed with the growing knowledge that such changes are important modifiers of cellular activation, it has become apparent that understanding the molecular mechanisms linking the physical tissue environment to the cell state is critical to our understanding of, and ultimately our ability to therapeutically address, fibrotic pathologies.

\section{Cellular mechanosensing in injury, repair, and fibrosis}

Cell mechanoresponses relevant to fibrosis. As early sentinels of homeostatic disruption, endothelial and epithelial cells have refined mechanosensing capabilities that allow them to detect fine changes in the physical environment. Multiple endothelial and epithelial mechanotransducers have been identified, including those in cell adhesion protein complexes, primary cilia, and mechanically gated ion channels (refs. 46-52 and Table 1). Mechanical activation of these sensory systems can alter endothelial and epithelial barrier function, inflammatory signaling, migration, invasion, and proliferation. Moreover, these cell types have the capacity to transmit signals to neighboring cells to amplify mechanoresponses. For example, endothelial cells are known to transmit signals to the surrounding microenvironment through angiocrine signals such as growth factors and chemokines (53). Epithelial cells similarly transmit paracrine signals that communicate mechanical signals to nearby mesenchyme (54). One particularly pertinent example is that of liver sinusoidal endothelial cells (LSECs), which actively secrete angiocrine signals that maintain neighboring hepatic stellate cell (HSC) quiescence (55), thereby preventing the "activation" or transdifferentiation of HSCs into fibrogenic myofibroblasts, key mediators of hepatic fibrosis. Studies suggest that LSECs are also capable of reverting HSCs from an activated to a quiescent phenotype through a nitric oxide-dependent pathway downstream of the mechanosensitive transcription factor Krüppellike factor 2 (KLF2) (56). Similar homeostatic epithelial signals in the lung are thought to underlie maintenance of fibroblast quiescence (57-59), while endothelial-derived angiocrine signals are implicated in lung regeneration and fibrosis (60).

Aberrant mechanical activation may underlie persistently altered endothelial and epithelial cell states in fibrosis. For example, vascular leakage and vasculopathies are implicated in fibrosis $(61,62)$, and vascular barrier function responds directly to mechanical forces $(63,64)$ and to alterations in matrix stiffness $(65-67)$. In the kidney, mechanical forces play a critical role in maintaining endothelial barrier function (68-70), while capillary functional alterations due to disturbed blood flow often lead to reduced vascular density, capillary rarefaction, and inflammation, which together exacerbate the progression of kidney fibrosis (71-73). Together these observations identify multiple potentially important roles for epithelial and endothelial mechanosignaling in acute injury responses and the transition to fibrotic tissue remodeling.

While tissue-resident interstitial mesenchymal cells (including organ-specific fibroblasts, pericytes, and stellate cells) respond to signals from epithelial and endothelial cells, they also directly respond to changes in their mechanical environment. Moreover, as the primary matrix-producing cells, they also have the capacity to remodel their tissue mechanical environment. For example, stretch promotes fibroblast matrix production (74), which reinforces the tissue and ultimately shields resident cells from further stretch in an attempt to restore mechanical homeostasis (4). In cases of pathological fibrotic remodeling, matrix stiffening promotes a nonhomeostatic feedback loop that amplifies matrix deposition in mesenchymal cells in a cell-autonomous fashion (27). Cultured lung fibroblasts, HSCs, and portal fibroblasts all respond to pathophysiological matrix stiffness changes with increased ECM gene expression, protein production, and deposition (27, 75-78). Relative to physiologically compliant matrices, stiff matrices promote characteristics of mesenchymal activation, including proliferation, apoptosis resistance, contractility, and expression of an invasive phenotype $(27,77,79)$. Together, these findings implicate fibrotic tissue stiffening in the amplification of mesenchymal cell activation. Intriguingly, dynamically altering matrix stiffness can recapitulate not just HSC activation upon matrix stiffening, but also partial reversion of the myofibroblastic phenotype upon matrix softening $(80,81)$, reinforcing the critical role of mechanics in determining mesenchymal cell fate. Similarly, pathological fibroblasts isolated from patients with idiopathic pulmonary fibrosis retain the capacity to become largely inactivated by culture on physiologically compliant matrices (82). These studies accentuate the need to identify the mechanisms that orchestrate fibroblast mechanobiological responses. 


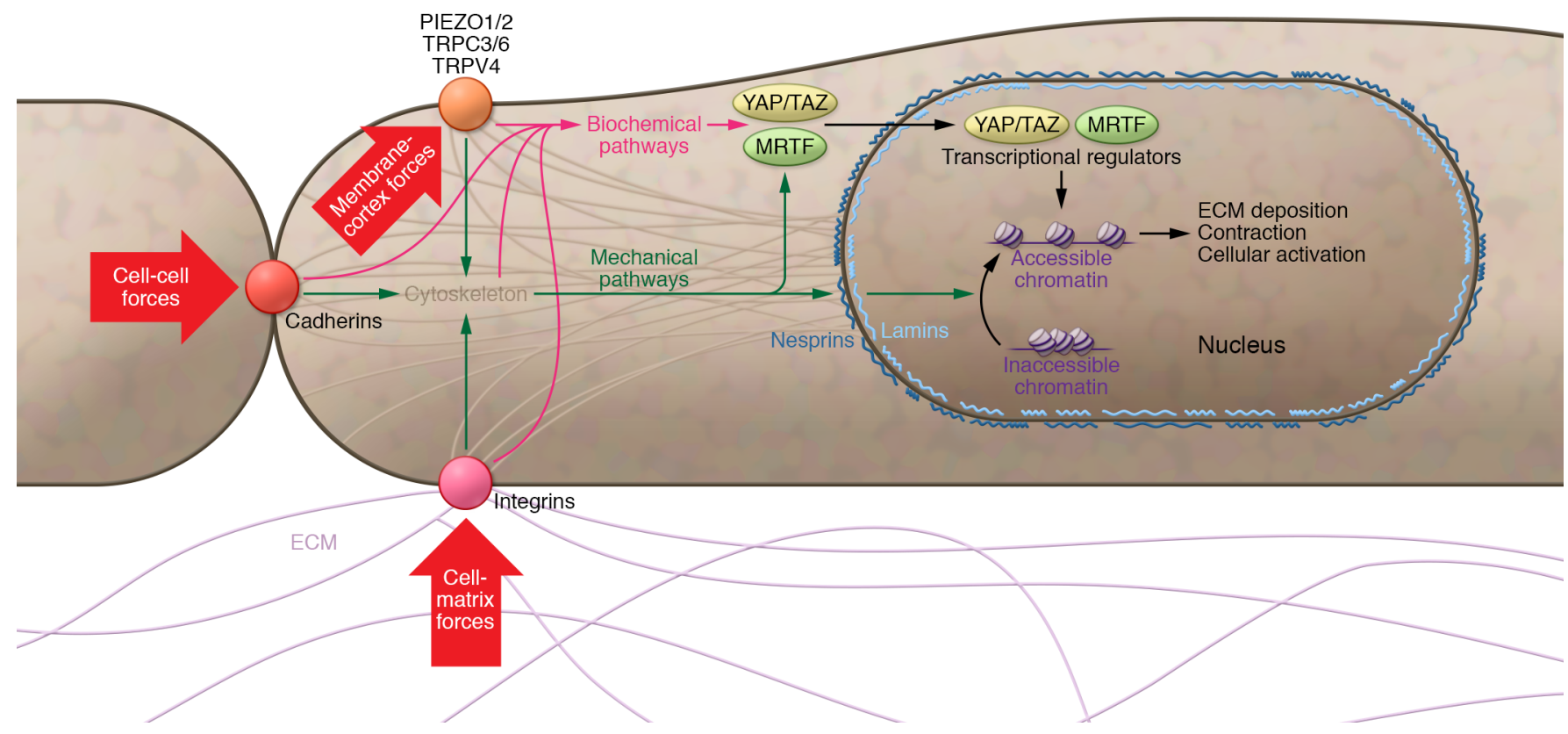

Figure 2. Mechanosensing mechanisms in injury, repair, and fibrosis. Cells receive mechanical cues via mechanosensitive proteins at the cell membranecytoskeletal cortex interface (e.g., PIEZ01/2), as well as cell-cell and cell-matrix adhesions, with cadherins and integrins being the most common mechanical signaling interfaces. Mechanical signal processing occurs through adhesion protein clustering, stabilization of protein-protein interactions (e.g., integrin-talin), and activation of biochemical and transcriptional signaling pathways. These signals may initiate at cell-cell or cell-matrix adhesion sites, or as a consequence of cytoskeletal remodeling (actin, myosin, Rho/ROCK) within the cytoplasm. Cytoskeletal remodeling can also transmit forces across the nuclear envelope (nesprins, lamins), potentially directly altering the environment for transcription. The combination of forces directly transmitted to the nucleus and the nuclear localization of mechanoactivated transcriptional regulators combine with a variety of epigenetic mechanisms to transiently or persistently alter cellular programs that drive injury, repair, and fibrosis responses.

Mechanisms of cell-matrix mechanosensing. Adherent cells derive critical signals from their interactions with the ECM to regulate survival, morphology, migration, and higher-level cell phenotypes. The mechanical information transmitted from the ECM is largely processed through integrin-based adhesions, which provide a mechanical linkage from the ECM to the intracellular cytoskeleton and cellular signaling pathways (ref. 83 and Figure 2). Integrins, comprising heterodimers of $\alpha$ and $\beta$ subunits, recognize specific polypeptide sequences in ECM proteins. In mechanosensing, integrins serve as mechanical linkages and scaffolds upon which complex signaling interactions can be organized, as their short intracellular domains have no inherent signaling domains (83). Activated integrins are bound to the actomyosin system through dynamic associations with integrin- or F-actinbinding proteins, such as talin and vinculin (84). Sensing of matrix stiffness by cultured fibroblasts requires the coordinated interactions of integrins with fibronectin outside the cell, and with talin and actin inside the cell. Together these dynamically interacting proteins form a clutch mechanism whereby competing adhesion, contraction, and adhesion-reinforcement kinetics enable mechanosensitive assembly, growth, and maintenance of integrin-based cell-matrix adhesion complexes (85). Specific integrin heterodimers display catch-bond behaviors $(86,87)$, with decreasing offrate kinetics under increased loading. This feature permits the mechanical environment to further impact the interactions and behavior of specific integrins. The GPI-anchored glycoprotein Thy- 1 has also recently been shown to modify integrin interactions (88), potentially amplifying or attenuating matrix stiffness sensi- tivity to cell-matrix adhesions. Adhesion complexes themselves are well known to integrate mechanical signals rapidly and thereby assemble on time scales immediately comparable to dynamic changes in internal or externally applied forces (89). Proteomics-based efforts have illuminated the tremendous complexity of cell-matrix adhesion complexes beyond the core integrin adhesion machinery, identifying more than 500 individual proteins in the adhesome as well as dynamic alterations in adhesome composition depending on changes in the mechanical environment $(90,91)$. Force-induced alterations to the composition, interactions, and activation state of signaling molecules within cellmatrix adhesions are thought to underlie the cellular response to the physical environment. However, the overwhelming complexity of these interactions has prompted a focus on downstream transcriptional points of signal integration (reviewed below), or on integrins themselves as upstream points of signal initiation.

Interest in targeting integrins in fibrosis originally gained momentum with the delineation of $\alpha_{v} \beta_{6}$ integrin as a key mechanism for extracellular TGF- $\beta$ activation, highlighting this integrin's therapeutic potential as a target in preclinical models of pulmonary and liver fibrosis (92-94). Studies expanded the investigation of integrin targeting to additional organs and introduced smallmolecule integrin inhibitors, particularly directed at the $\alpha_{v}$ subunit (95-99). Recent cell biological studies reveal an important role for $\alpha_{\mathrm{v}}$ integrins in mechanosensing $(100,101)$, potentially linking these integrins to mechanobiological responses that occur in fibrotic tissue remodeling. Thus while integrin targeting remains complicated by the relatively limited repertoire and broad tissue distribution 
of these key cell adhesion proteins, along with the complex intracellular signaling cascades triggered by cell adhesion, the promising results in preclinical models suggest the potential for integrins to emerge as viable therapeutic targets in fibrosis.

Cell-cell mechanosensing. Cells also derive important information, including mechanical signals, from cell-cell adhesions. The most studied of the cell-cell adhesion mechanotransducers are cadherin-based adhesions, which form via homotypic interactions between membrane-spanning cadherins on adjacent cells (ref. 102 and Figure 2). As in cell-matrix adhesions, the physical state of actomyosin tension plays an important role in the formation, organization, and downstream signaling from these cell-cell adhesion complexes, while the junctions themselves provide signals that regulate cell polarity, collective migration, barrier function, and cell state. Forces transmitted across cell-cell adhesions contribute to long-range tissue integrity and morphogenesis (103) and are essential to collective migration (104). A well-described endothelial mechanotransducing complex that mediates responses to luminal shear is localized at cell-cell junctions and contains VE-cadherin, PECAM-1, and two VEGF receptors, VEGFR2 and VEGFR3 (105-110). Flow and mechanical force trigger engagement of PECAM-1 with the vimentin cytoskeleton and activation of an Src family kinase, leading to sequential activation of VEGF receptors, PI3K, and endothelial nitric oxide synthase, and generation of nitric oxide to regulate vascular tone. VEGF receptor tyrosine kinase inhibitors are well-tolerated therapies used to treat various malignancies, and preclinical studies show promise in promoting deactivation of myofibroblasts and treatment of fibrosis (111).

Beyond shear sensing, cell-cell adhesions are critical to barrier function. Internally generated cytoskeletal forces or externally generative physical forces can disrupt cell-cell adhesion, altering both mechanical homeostasis and barrier function (64). Recently, physical cues have been identified as important regulators of cellcell signaling via the Notch pathway (112-114), with significant therapeutic implications for pulmonary, dermal, and renal fibrosis $(60,115,116)$. Thus, cell-cell adhesions provide both mechanical and biochemical signals that are likely relevant to both endothelial and epithelial injury, as well as the transition from injury to healing or fibrotic scarring. While less appreciated, interstitial cells such as fibroblasts also express cadherins that mediate physical cell-cell signaling cues to modulate cell phenotype $(117,118)$, and recent studies specifically implicate cadherin 11 in fibrotic tissue remodeling (119).

\section{Transcriptional mechanosensing effectors}

While cell-matrix and cell-cell adhesions are clearly key points of initiation for cell mechanosensing, their importance to normal physiology and the complexity of the downstream signaling mechanisms they engage present barriers to potential therapeutic intervention. Such complexity has been an important driver of efforts to identify downstream points of convergence in mechanical signaling implicated in fibrosis, with a focus on transcriptional effectors as rheostats that tune cell activation in response to mechanical cues. While a number of transcription factors have been implicated in mechanosensing (120), we focus here on YAP and TAZ and myocardin-related transcription factor (MRTF), which appear to be central coordinators of fibrosis-relevant mechanical responses in mesenchymal cells.
YAP and TAZ activate fibroblasts downstream of mechanosensing. The transcriptional cofactors YAP and TAZ were identified by Dupont et al. (121) as robust mechanosensors in endothelial cells and mesenchymal stromal cells, translocating from the cytoplasm to the nucleus depending on matrix stiffness. Beyond mechanosensing, they serve as central nodes in cell signaling downstream of cell-cell adhesion, cell-matrix adhesion, and cytoskeletal signaling, in addition to regulation by metabolic and receptor-mediated signaling pathways (122). YAP and TAZ are directly regulated by the kinases LATS1 and LATS2, with YAP/TAZ phosphorylation resulting in cytoplasmic sequestration or degradation (122). The precise mechanosensing mechanisms that regulate YAP/ TAZ nuclear shuttling are still being defined. YAP and TAZ lack DNA-binding domains themselves, but mediate transcriptional effects predominantly through TEA domain factors TEAD1-4, as well as through interactions with several families of transcription factors that have been directly implicated in fibrosis, such as SMADs (downstream of TGF- $\beta$ and BMP) and $\beta$-catenin (123). In epithelial cells, YAP and TAZ mediate cell survival signaling, confer stem cell and reparative programs, promote mesenchymal transitions, and play roles in oncogenesis (122). Recent work in lung, liver, kidney, and dermal fibroblasts implicates a conserved and pivotal role for YAP and TAZ in activating these cells toward profibrotic states (124-129). Verteporfin, a small-molecule inhibitor of YAP/TAZ interactions with TEADs, demonstrates promising proof-of-concept efficacy in preclinical fibrosis models (126, 127). Together, these studies suggest central roles for YAP and TAZ in the fibrogenic cascade. Problematically, YAP and TAZ are widely expressed and important in numerous organ and tissue contexts, posing challenges to therapeutic targeting of this pathway. Interestingly, Rho/ROCK signaling appears to be a pivotal upstream regulator of both mechanical and receptor-mediated YAP and TAZ activation $(121,130)$, suggesting that positive results with ROCK inhibitors in preclinical fibrosis models may reflect, in part, reduced YAP/TAZ activation $(131,132)$. Ongoing efforts to identify genetic and molecular targets for YAP/TAZ selective inhibition may provide novel approaches to interrupt mechanical and receptor-mediated signals that promote fibroblast activation. Given their widespread expression and pleiotropic roles, identification of selective points for YAP and TAZ inhibition may be essential if their therapeutic potential is to be realized.

MRTFs coordinate profibrotic signaling in myofibroblasts. MRTF-A and -B (also referred to as MKL1 and MKL2) share many functional features with YAP and TAZ. Unlike YAP and TAZ, MRTFs are sequestered in the cytoplasm bound to G-actin, and their nuclear export and transcriptional interactions are regulated by G-actin interactions within the nucleus (133). MRTF-A responds to increases in actin cytoskeleton assembly (decreased G-actin) with nuclear translocation and transcriptional function, while actin cytoskeleton disassembly results in nuclear export $(133,134)$. Within the nucleus, these factors interact with serum response factor (SRF) to regulate gene programs $(135,136)$, including a prominent role in regulation of contractile machinery genes in smooth muscle cells and myofibroblasts $(75,137,138)$. Similar to YAP and TAZ, MRTF is a major transcriptional regulator downstream of profibrotic signals, including TGF- $\beta$ and Rho/ROCK pathways $(135,138,139)$. It also plays an important role in stiff- 
ness-dependent fibroblast function (75). Genetic deletion or pharmacological inhibition of MRTF attenuates fibrotic tissue remodeling (137, 139-143), while small-molecule activation of MRTF accentuates myofibroblast activation and wound healing (144).

While YAP/TAZ and MRTF/SRF were originally thought to have distinct effects on downstream gene transcription (121), several recent studies demonstrate overlapping effects and direct interactions between these pathways that suggest context-dependent cooperative and potentially counterbalancing effects (145-148). The hierarchical relationships between these two transcriptional regulatory families are likely to be complex and to encompass reciprocal interactions at the protein and transcript levels, in addition to interactions with epigenetic cell states (detailed below). Further elucidation of the interactive roles of MRTF with YAP/TAZ, as well as delineation of critical nodes in their upstream activation, is likely to provide new avenues for controlling cell fate in tissue injury and remodeling.

\section{Mechanical regulation of nuclear dynamics in fibrogenic diseases}

Signaling to the nucleus via transcription factors is not the only mechanism by which physical forces alter transcriptional responses, as studies show that biomechanical signals can also propagate to the cell nucleus via cytoskeletal linkages (ref. 149 and Figure 2). Several key mechanosensing proteins that connect the nuclear lamina to the cytoskeleton have been identified (150-155). These critical structural components of the nuclear lamina, such as lamins and nesprins (which form the LINC complex), can directly interact and control chromatin organization, thereby restricting or promoting the accessibility of transcription factors to specific genetic loci (156-160). In a recent paper, Alam and colleagues showed that the increased cell spreading and traction forces that occur on stiff substrates compared with soft substrates alter nuclear stresses, which in turn impact gene transcription (156). This study and others suggest that nucleus-cytoskeleton interconnectivity regulates genome-wide transcriptional responses to substrate rigidity (156, 161, 162). These observations raise the possibility that alterations in tissue mechanical environments may directly influence nuclear architecture and gene transcription during injury and fibrotic tissue remodeling, and suggest that increases in matrix stiffness may contribute to persistent global changes in gene transcription.

A number of studies have shown that loss of integration between actin cytoskeletal filaments and mechanosensitive components of the nuclear lamina alters the transcriptional machinery and leads to mesenchymal dysfunction and organ fibrosis (163, 164). Absence of lamins or mutations in these structural nuclear components often lead to an impaired cellular response to mechanical stress and disturbances in cytoskeletal organization resulting in increased tissue fibrosis $(165,166)$. Mouse fibroblasts deficient in LMNA (encoding lamin A/C) display defective TGF- $\beta$ signaling that leads to increased cell proliferation and collagen production (167). In skeletal muscle, lack of the lamin A-binding protein nesprin 1 reduces connectivity of the nuclear envelope to the actin cytoskeleton, resulting in severe fibrotic tissue responses and altered local tissue stiffness (165). Moreover, it has been shown that the lamin A-interacting proteins MAN1 and emerin can control TGF- $\beta$ signaling by binding and sequestering SMAD proteins at the nuclear periphery, resulting in deficient SMAD/DNA interactions and altered TGF- $\beta$ responses $(168,169)$. Additionally, lamin $A$ and emerin can modulate actin polymerization to control nuclear localization and activation of MRTF, suggesting the existence of a feedback loop between mechanical and biochemical regulation of profibrotic gene transcription (170). More broadly, patients bearing mutations in the LMNA gene develop genetic disorders called laminopathies, which are characterized by tissue fibrosis $(171,172)$. Interestingly, laminopathies display clinical phenotypes comparable to those seen for diseases resulting from genetic defects in cytoskeletal components $(173,174)$, further indicating that alterations in the mechanocoupling between the cytoskeleton and nuclear envelope, which plays a central role in maintaining the cell's mechanical properties, may promote fibrosis.

\section{Epigenetic mechanoresponses}

Integration of mechanosignaling with epigenetic machinery. Epigenetics, including DNA methylation, histone modification/ chromatin remodeling, and RNA-based machinery, refers to the study of heritable changes in gene expression that occur without changes in the DNA sequence. Previous studies have shown that epigenetic alterations regulate gene expression and contribute to the development of numerous diseases, including fibroproliferative disorders (175-177). Altered epigenetic mechanisms may be responsible for perpetuating the activated state of scar-associated fibroblasts by modulating the transcriptional activity of genes involved in fibrosis progression (178).

While the biochemical signals driving epigenetic changes during fibroblast activation are well established (175-177), the role of mechanical force-induced epigenetic modifications and chromatin remodeling in regulating mesenchymal cell behavior is still emerging. Recent studies show that mechanical cues and matrix stiffness can affect nuclear functions including chromatin organization and global epigenetic state of the cells (179-181). Based on the knowledge that epigenetic information passes from cell to cell through cell divisions, mechanical forces may exert long-term changes to gene expression by altering the epigenetic landscape. Emerging studies shed light on the influence of actin cytoskeleton on chromatin organization and its accessibility to the transcription machinery $(180,182,183)$. It was recently proposed that alterations in cytoskeleton tension are correlated to changes in the levels of histone acetylation (184), and mechanical stress has been linked to an increase in histone 3 (H3) and $\mathrm{H} 4$ acetylation, thereby promoting formation of transcriptionally active chromatin. One mechanism by which mechanical stress alters histone acetylation is through actin filament-mediated sequestration of histone deacetylases (HDACs), suggesting that cell cytoskeleton can directly alter gene expression by regulating the nuclear shuttling of epigenetic regulators (185). Consequently, inhibition of actin-myosin contractility with blebbistatin impairs mechanical stress-driven chromatin alteration (185).

Previous studies have shown that TGF- $\beta$ induces deposition of $\mathrm{H} 3$ lysine 4 ( $\mathrm{H} 3 \mathrm{~K} 4)$ marks on profibrotic gene promoters in fibroblasts that are crucial to their profibrotic activity (186). Interestingly, the binding of SMADs to their target promoters during TGF- $\beta$-stimulated fibroblast activation is modulated by H3K4 methylation in an MRTF-A-dependent manner $(186,187)$. MRTF-A silencing in fibroblasts has profound impact on chroma- 
tin structure that results in reduced deposition of H3K4 methylation marks on profibrogenic promoters as well as deficient TGF- $\beta$ responses (187). These observations support the concept that mechanical effects alter the chromatin landscape of fibroblasts to create a profibrogenic signature.

Although physical transmission of mechanical forces to the nucleus may directly control spatial chromatin organization and gene expression, biochemical signals further alter these responses. In myofibroblast differentiation and fibrosis, mechanoregulation of the epigenetic landscape in fibroblasts may generate the necessary conditions to receive biochemical signals that permit the continuation of myofibroblast differentiation. Understanding how biochemical and mechanical signals interact to regulate chromatin assembly and gene transcription may lead to the development of new therapeutic strategies to ameliorate fibrosis progression.

Epigenetic influence of mechanical memory. A growing body of evidence supports the notion that cells not only respond transiently to mechanical signals, but can also "memorize" mechanical information presented by the local microenvironment and integrate such information through epigenetic mechanisms (188). It has been proposed that mechanical memory retained by fibroblasts may have long-term effects on these cells, thereby influencing cell fate decisions $(188,189)$. A recent paper by Li and colleagues reveals an important link between mechanical memory and miR-21 synthesis (190). miR-21 has been shown to regulate the transcription of numerous profibrotic genes in fibroblasts and has been proposed as a potential therapeutic target in fibrosis (191, 192). Li and colleagues showed that freshly isolated mesenchymal stem cells cultured for several passages on supraphysiological stiff substrates (tissue culture dishes) upregulate miR-21 expression and subsequently acquire scarring features that persist after these cells are subcultured on compliant substrates. Moreover, they demonstrated that the mechanoregulator MRTF-A promotes miR21 transcription in cells cultured on stiff substrate but fails to do so in cells cultured on soft substrates. These observations, while not yet established in the context of tissue fibrosis and resident mesenchymal cells, suggest that MRTF-A may integrate mechanical signals from the local cellular microenvironment with epigenetic control of gene transcription to induce persistent profibrotic behaviors that perpetuate disease progression.

Taken together, these observations support a potentially crucial role for epigenetic mechanisms in linking mechanosensing to fibrogenic disorders. While rapid advances have been made in development of pharmacological tools to target the epigenetic landscape $(193,194)$ and several epigenetic therapies have already been approved for cancer treatment $(195,196)$, no epigenetic drugs for the treatment of fibrotic diseases have yet reached the clinical arena. Based on the emerging links between mechanical forces and epigenetic regulatory mechanisms, and the apparent crosstalk between mechanosensitive transcriptional effectors and chromatin dynamics, it may be possible to identify therapeutic strategies that target the epigenetic machinery of diseased cells to efficiently "erase" their persistent fibrogenic memory and reestablish their quiescent state.

\section{Conclusions}

Mechanical homeostasis, the capacity to generate and maintain an organ- and tissue-level mechanical environment that supports function, is a hallmark of physiological systems. Injury fundamentally alters mechanical homeostasis and initiates reparative processes that include recruitment and activation of resident mesenchymal cells. As summarized here, we believe that fibrosis ultimately represents a failure to reestablish mechanical homeostasis, thereby engaging a default pathway of mechanosensitive cellular activation through cell-matrix-mediated transcriptional and epigenetic mechanisms, leading to progressive ECM deposition and tissue destruction. Recent advances in the study of tissue repair, fibrosis, and mechanosensory signaling mechanisms have begun to reveal how mechanical environments form in normal, injured, repairing, and fibrotic tissue and how these environments are maintained and signal to resident cells. Translating these insights into clinical and therapeutic interventions may enable new approaches to treat fibrotic tissue remodeling.

\section{Acknowledgments}

This work was supported by grants from the NIH (HL092961, to DJT; HL133320, to DJT and VHS; and NIAAA21171, to VHS). We apologize to our colleagues whose work we were unable to discuss because of space limitations.

Address correspondence to: Daniel J. Tschumperlin, Mayo Clinic, Department of Physiology and Biomedical Engineering, 200 First Street SW, Rochester, Minnesota 55905, USA. Phone: 507.255.8475; E-mail: Tschumperlin.Daniel@mayo.edu.
1. Eyckmans J, Boudou T, Yu X, Chen CS. A hitchhiker's guide to mechanobiology. Dev Cell. 2011;21(1):35-47.

2. Mammoto T, Mammoto A, Ingber DE. Mechanobiology and developmental control. Annu Rev Cell Dev Biol. 2013;29:27-61.

3. DuFort CC, Paszek MJ, Weaver VM. Balancing forces: architectural control of mechanotransduction. Nat Rev Mol Cell Biol. 2011;12(5):308-319.

4. Humphrey JD, Dufresne ER, Schwartz MA. Mechanotransduction and extracellular matrix homeostasis. Nat Rev Mol Cell Biol. 2014;15(12):802-812.

5. Pellicoro A, Ramachandran P, Iredale JP, Fallowfield JA. Liver fibrosis and repair: immune regulation of wound healing in a solid organ. Nat Rev
Immunol. 2014;14(3):181-194.

6. Wynn TA. Integrating mechanisms of pulmonary fibrosis. JExp Med. 2011;208(7):1339-1350.

7. Huse M. Mechanical forces in the immune system [published online ahead of print July 31, 2017]. Nat Rev Immunol. https://doi.org/10.1038/ nri.2017.74.

8. Leung LY, Tian D, Brangwynne CP, Weitz DA, Tschumperlin DJ. A new microrheometric approach reveals individual and cooperative roles for TGF- $\beta 1$ and IL- $1 \beta$ in fibroblastmediated stiffening of collagen gels. FASEB J. 2007;21(9):2064-2073.

9. Wang Q, et al. Changes in the biomechanical properties of neutrophils and endothelial cells during adhesion. Blood. 2001;97(3):660-668.
10. Yang MT, Reich DH, Chen CS. Measurement and analysis of traction force dynamics in response to vasoactive agonists. Integr Biol (Camb). 2011;3(6):663-674.

11. Wiig H, Swartz MA. Interstitial fluid and lymph formation and transport: physiological regulation and roles in inflammation and cancer. Physiol Rev. 2012;92(3):1005-1060.

12. Jansen KA, Bacabac RG, Piechocka IK, Koenderink GH. Cells actively stiffen fibrin networks by generating contractile stress. Biophys J. 2013;105(10):2240-2251.

13. Wen Q, Janmey PA. Effects of non-linearity on cell-ECM interactions. Exp Cell Res. 2013;319(16):2481-2489.

14. Chopra A, et al. Augmentation of integrin- 
mediated mechanotransduction by hyaluronic acid. Biomaterials. 2014;35(1):71-82.

15. Sunyer R, et al. Collective cell durotaxis emerges from long-range intercellular force transmission. Science. 2016;353(6304):1157-1161.

16. Georges PC, et al. Increased stiffness of the rat liver precedes matrix deposition: implications for fibrosis. Am J Physiol Gastrointest Liver Physiol. 2007;293(6):G1147-G1154.

17. Thannickal VJ, Zhou Y, Gaggar A, Duncan SR. Fibrosis: ultimate and proximate causes. JClin Invest. 2014;124(11):4673-4677.

18. Wynn TA. Common and unique mechanisms regulate fibrosis in various fibroproliferative diseases. J Clin Invest. 2007;117(3):524-529.

19. Kulkarni T, de Andrade J, Zhou Y, Luckhardt T, Thannickal VJ. Alveolar epithelial disintegrity in pulmonary fibrosis. Am J Physiol Lung Cell Mol Physiol. 2016;311(2):L185-L191.

20. Desmoulière A, Redard M, Darby I, Gabbiani G. Apoptosis mediates the decrease in cellularity during the transition between granulation tissue and scar. Am J Pathol. 1995;146(1):56-66.

21. Hinz B, Mastrangelo D, Iselin CE, Chaponnier C, Gabbiani G. Mechanical tension controls granulation tissue contractile activity and myofibroblast differentiation. Am J Pathol. 2001;159(3):1009-1020.

22. Aarabi S, et al. Mechanical load initiates hypertrophic scar formation through decreased cellular apoptosis. FASEB J. 2007;21(12):3250-3261.

23. Gurtner GC, et al. Improving cutaneous scar formation by controlling the mechanical environment: large animal and phase I studies. Ann Surg. 2011;254(2):217-225.

24. Kisseleva T, et al. Myofibroblasts revert to an inactive phenotype during regression of liver fibrosis. Proc Natl Acad Sci U S A. 2012;109(24):9448-9453.

25. Glasser SW, Hagood JS, Wong S, Taype CA, Madala SK, Hardie WD. Mechanisms of lung fibrosis resolution. Am J Pathol. 2016;186(5):1066-1077.

26. Wells RG. Tissue mechanics and fibrosis. Biochim Biophys Acta. 2013;1832(7):884-890.

27. Liu F, et al. Feedback amplification of fibrosis through matrix stiffening and COX-2 suppression. J Cell Biol. 2010;190(4):693-706.

28. Booth AJ, et al. Acellular normal and fibrotic human lung matrices as a culture system for in vitro investigation. Am J Respir Crit Care Med. 2012;186(9):866-876.

29. Parker MW, et al. Fibrotic extracellular matrix activates a profibrotic positive feedback loop. J Clin Invest. 2014;124(4):1622-1635.

30. Southern BD, et al. Matrix-driven myosin II mediates the pro-fibrotic fibroblast phenotype. J Biol Chem. 2016;291(12):6083-6095.

31. Tschumperlin DJ. Matrix, mesenchyme, and mechanotransduction. Ann Am Thorac Soc. 2015;12(suppl 1):S24-S29.

32. Baker BM, et al. Cell-mediated fibre recruitment drives extracellular matrix mechanosensing in engineered fibrillar microenvironments. Nat Mater. 2015;14(12):1262-1268.

33. Dingal PC, et al. Fractal heterogeneity in minimal matrix models of scars modulates stiff-niche stem-cell responses via nuclear exit of a mecha- norepressor. Nat Mater. 2015;14(9):951-960.

34. Thannickal VJ, et al. Matrix biology of idiopathic pulmonary fibrosis: a workshop report of the national heart, lung, and blood institute. Am J Pathol. 2014;184(6):1643-1651.

35. Jayes FL, Liu B, Moutos FT, Kuchibhatla M, Guilak F, Leppert PC. Loss of stiffness in collagen-rich uterine fibroids after digestion with purified collagenase Clostridium histolyticum. Am JObstet Gynecol. 2016;215(5):596.e1-596.e8.

36. Liu SB, et al. Lysyl oxidase activity contributes to collagen stabilization during liver fibrosis progression and limits spontaneous fibrosis reversal in mice. FASEB J. 2016;30(4):1599-1609.

37. Rosin NL, Sopel MJ, Falkenham A, Lee TD, Légaré JF. Disruption of collagen homeostasis can reverse established age-related myocardial fibrosis. Am J Pathol. 2015;185(3):631-642.

38. Barry-Hamilton V, et al. Allosteric inhibition of lysyl oxidase-like-2 impedes the development of a pathologic microenvironment. Nat Med. 2010;16(9):1009-1017.

39. Ikenaga N, et al. Selective targeting of lysyl oxidase-like 2 (LOXL2) suppresses hepatic fibrosis progression and accelerates its reversal. Gut. 2017;66(9):1697-1708.

40. Raghu G, et al. Efficacy of simtuzumab versus placebo in patients with idiopathic pulmonary fibrosis: a randomised, double-blind, controlled, phase 2 trial. Lancet Respir Med. 2017;5(1):22-32.

41. Steppan J, et al. Tissue transglutaminase modulates vascular stiffness and function through crosslinking-dependent and crosslinking-independent functions. J Am Heart Assoc. 2017;6(2):e004161.

42. Vicens-Zygmunt V, et al. Fibroblast viability and phenotypic changes within glycated stiffened three-dimensional collagen matrices. Respir Res. 2015;16:82.

43. Naba A, Clauser KR, Ding H, Whittaker CA, Carr SA, Hynes RO. The extracellular matrix: tools and insights for the "omics" era. Matrix Biol. 2016;49:10-24.

44. Rashid ST, et al. Proteomic analysis of extracellular matrix from the hepatic stellate cell line LX-2 identifies CYR61 and Wnt-5a as novel constituents of fibrotic liver.J Proteome Res. 2012;11(8):4052-4064.

45. Schiller HB, et al. Time- and compartment-resolved proteome profiling of the extracellular niche in lung injury and repair. Mol Syst Biol. 2015;11(7):819.

46. Li YS, Haga JH, Chien S. Molecular basis of the effects of shear stress on vascular endothelial cells. J Biomech. 2005;38(10):1949-1971.

47. Wang S, et al. P2Y ${ }_{2}$ and $\mathrm{Gq} / \mathrm{G}_{11}$ control blood pressure by mediating endothelial mechanotransduction. JClin Invest. 2015;125(8):3077-3086.

48. Goetz JG, et al. Endothelial cilia mediate low flow sensing during zebrafish vascular development. Cell Rep. 2014;6(5):799-808.

49. Hahn C, Schwartz MA. Mechanotransduction in vascular physiology and atherogenesis. Nat Rev Mol Cell Biol. 2009;10(1):53-62.

50. Coste B, et al. Piezo proteins are pore-forming subunits of mechanically activated channels. Nature. 2012;483(7388):176-181.

51. Gudipaty SA, et al. Mechanical stretch triggers rapid epithelial cell division through Piezo1. Nature. 2017;543(7643):118-121.

52. Wang S, Chennupati R, Kaur H, Iring A, Wettschureck N, Offermanns S. Endothelial cation channel PIEZO1 controls blood pressure by mediating flow-induced ATP release. JClin Invest. 2016;126(12):4527-4536.

53. Ding BS, et al. Divergent angiocrine signals from vascular niche balance liver regeneration and fibrosis. Nature. 2014;505(7481):97-102.

54. Swartz MA, Tschumperlin DJ, Kamm RD, Drazen JM. Mechanical stress is communicated between different cell types to elicit matrix remodeling. Proc Natl Acad Sci U S A. 2001;98(11):6180-6185.

55. Xie G, et al. Role of differentiation of liver sinusoidal endothelial cells in progression and regression of hepatic fibrosis in rats. Gastroenterology. 2012;142(4):918-927.e6.

56. Marrone G, et al. The transcription factor KLF2 mediates hepatic endothelial protection and paracrine endothelial-stellate cell deactivation induced by statins. J Hepatol. 2013;58(1):98-103.

57. Epa AP, et al. Normal human lung epithelial cells inhibit transforming growth factor- $\beta$ induced myofibroblast differentiation via prostaglandin E2. PLoS One. 2015;10(8):e0135266.

58. Lama V, Moore BB, Christensen P, Toews GB, Peters-Golden M. Prostaglandin E2 synthesis and suppression of fibroblast proliferation by alveolar epithelial cells is cyclooxygenase2-dependent. Am J Respir Cell Mol Biol. 2002;27(6):752-758.

59. Pan T, Mason RJ, Westcott JY, Shannon JM. Rat alveolar type II cells inhibit lung fibroblast proliferation in vitro. Am J Respir Cell Mol Biol. 2001;25(3):353-361.

60. Cao Z, et al. Targeting of the pulmonary capillary vascular niche promotes lung alveolar repair and ameliorates fibrosis. Nat Med. 2016;22(2):154-162.

61. Tager AM, et al. The lysophosphatidic acid receptor LPA1 links pulmonary fibrosis to lung injury by mediating fibroblast recruitment and vascular leak. Nat Med. 2008;14(1):45-54.

62. Varga J, Abraham D. Systemic sclerosis: a prototypic multisystem fibrotic disorder. J Clin Invest. 2007;117(3):557-567.

63. Birukov KG, et al. Magnitude-dependent regulation of pulmonary endothelial cell barrier function by cyclic stretch. Am J Physiol Lung Cell Mol Physiol. 2003;285(4):L785-L797.

64. Dudek SM, Garcia JG. Cytoskeletal regulation of pulmonary vascular permeability. J Appl Physiol. 2001;91(4):1487-1500.

65. Birukova AA, Tian X, Cokic I, Beckham Y, Gardel ML, Birukov KG. Endothelial barrier disruption and recovery is controlled by substrate stiffness. Microvasc Res. 2013;87:50-57.

66. Bordeleau F, et al. Matrix stiffening promotes a tumor vasculature phenotype. Proc Natl Acad Sci US A. 2017;114(3):492-497.

67. Huynh J, et al. Age-related intimal stiffening enhances endothelial permeability and leukocyte transmigration. Sci Transl Med. 2011;3(112):112ra122.

68. Basile DP. The endothelial cell in ischemic acute kidney injury: implications for acute and chronic function. Kidney Int. 2007;72(2):151-156.

69. Lemos DR, et al. Maintenance of vascular 
integrity by pericytes is essential for norma kidney function. Am J Physiol Renal Physiol. 2016;311(6):F1230-F1242.

70. Ligresti G, et al. A novel three-dimensional human peritubular microvascular system. J Am Soc Nephrol. 2016;27(8):2370-2381.

71. Duffield JS. Cellular and molecular mechanisms in kidney fibrosis. JClin Invest. 2014;124(6):2299-2306

72. Kida Y, Ieronimakis N, Schrimpf C, Reyes M, Duffield JS. EphrinB2 reverse signaling protects against capillary rarefaction and fibrosis after kidney injury. JAm Soc Nephrol. 2013;24(4):559-572.

73. Tanaka T, Nangaku M. Angiogenesis and hypoxia in the kidney. Nat Rev Nephrol.2013;9(4):211-222.

74. Herum KM, Choppe J, Kumar A, Engler AJ, McCulloch AD. Mechanical regulation of cardiac fibroblast profibrotic phenotypes. Mol Biol Cell. 2017;28(14):1871-1882.

75. Huang X, et al. Matrix stiffness-induced myofibroblast differentiation is mediated by intrinsic mechanotransduction. Am J Respir Cell Mol Biol. 2012;47(3):340-348

76. Li Z, Dranoff JA, Chan EP, Uemura M, Sévigny J, Wells RG. Transforming growth factor-beta and substrate stiffness regulate portal fibroblast activation in culture. Hepatology. 2007;46(4):1246-1256.

77. Marinković A, Mih JD, Park JA, Liu F, Tschumperlin DJ. Improved throughput traction microscopy reveals pivotal role for matrix stiffness in fibroblast contractility and TGF- $\beta$ responsiveness. Am J Physiol Lung Cell Mol Physiol. 2012;303(3):L169-L180.

78. Olsen AL, et al. Hepatic stellate cells require a stiff environment for myofibroblastic differentiation. Am J Physiol Gastrointest Liver Physiol. 2011;301(1):G110-G118.

79. Chen $\mathrm{H}$, et al. Mechanosensing by the $\alpha 6-$ integrin confers an invasive fibroblast phenotype and mediates lung fibrosis. Nat Commun. 2016;7:12564.

80. Caliari SR, Perepelyuk M, Soulas EM, Lee GY, Wells RG, Burdick JA. Gradually softening hydrogels for modeling hepatic stellate cell behavior during fibrosis regression. Integr Biol (Camb). 2016;8(6):720-728.

81. Caliari SR, et al. Stiffening hydrogels for investigating the dynamics of hepatic stellate cell mechanotransduction during myofibroblast activation. Sci Rep. 2016;6:21387.

82. Marinković A, Liu F, Tschumperlin DJ. Matrices of physiologic stiffness potently inactivate idiopathic pulmonary fibrosis fibroblasts. Am J Respir Cell Mol Biol. 2013;48(4):422-430.

83. Hynes RO. Integrins: bidirectional, allosteric signaling machines. Cell. 2002;110(6):673-687.

84. Sun Z, Guo SS, Fässler R. Integrin-mediated mechanotransduction. J Cell Biol. 2016;215(4):445-456.

85. Elosegui-Artola A, et al. Mechanical regulation of a molecular clutch defines force transmission and transduction in response to matrix rigidity. Nat Cell Biol. 2016;18(5):540-548.

86. Fiore VF, Ju L, Chen Y, Zhu C, Barker TH. Dynamic catch of a Thy-1- $\alpha 5 \beta 1+$ syndecan- 4 trimolecular complex. Nat Commun. 2014;5:4886.

87. Kong F, García AJ, Mould AP, Humphries MJ, Zhu C. Demonstration of catch bonds between an integrin and its ligand. J Cell Biol. 2009;185(7):1275-1284.

88. Fiore VF, Strane PW, Bryksin AV, White ES, Hagood JS, Barker TH. Conformational coupling of integrin and Thy-1 regulates Fyn priming and fibroblast mechanotransduction. J Cell Biol. 2015;211(1):173-190.

89. Balaban NQ, et al. Force and focal adhesion assembly: a close relationship studied using elastic micropatterned substrates. Nat Cell Biol. 2001;3(5):466-472.

90. Kuo JC, Han X, Hsiao CT, Yates JR, Waterman $\mathrm{CM}$. Analysis of the myosin-II-responsive focal adhesion proteome reveals a role for $\beta$-Pix in negative regulation of focal adhesion maturation. Nat Cell Biol. 2011;13(4):383-393.

91. Schiller HB, Friedel CC, Boulegue C, Fässler R. Quantitative proteomics of the integrin adhesome show a myosin II-dependent recruitment of LIM domain proteins. EMBO Rep. 2011;12(3):259-266.

92. Horan GS, et al. Partial inhibition of integrin alpha(v)beta6 prevents pulmonary fibrosis without exacerbating inflammation. Am J Respir Crit Care Med. 2008;177(1):56-65.

93. Munger JS, et al. The integrin $\alpha v \beta 6$ binds and activates latent TGF- $\beta 1$ : a mechanism for regulating pulmonary inflammation and fibrosis. Cell. 1999;96(3):319-328.

94. Patsenker E, Popov Y, Stickel F, Jonczyk A, Goodman SL, Schuppan D. Inhibition of integrin alphavbeta6 on cholangiocytes blocks transforming growth factor-beta activation and retards biliary fibrosis progression. Gastroenterology. 2008;135(2):660-670.

95. Chang Y, et al. Pharmacologic blockade of av $\beta 1$ integrin ameliorates renal failure and fibrosis in vivo. J Am Soc Nephrol. 2017;28(7):1998-2005.

96. Henderson NC, et al. Targeting of av integrin identifies a core molecular pathway that regulates fibrosis in several organs. Nat Med. 2013;19(12):1617-1624.

97. Peng ZW, et al. Integrin $\alpha v \beta 6$ critically regulates hepatic progenitor cell function and promotes ductular reaction, fibrosis, and tumorigenesis. Hepatology. 2016;63(1):217-232.

98. Reed NI, et al. The $\alpha v \beta 1$ integrin plays a critical in vivo role in tissue fibrosis. Sci Transl Med. 2015;7(288):288ra79.

99. Minagawa $S$, et al. Selective targeting of TGF- $\beta$ activation to treat fibroinflammatory airway disease. Sci Transl Med. 2014;6(241):241ra79.

100.Elosegui-Artola A, et al. Rigidity sensing and adaptation through regulation of integrin types. Nat Mater. 2014;13(6):631-637.

101.Schiller HB, et al. $\beta 1$ - and $\alpha$-class integrins cooperate to regulate myosin II during rigidity sensing of fibronectin-based microenvironments. Nat Cell Biol. 2013;15(6):625-636

102. Leckband DE, de Rooij J. Cadherin adhesion and mechanotransduction. Annu Rev Cell Dev Biol. 2014;30:291-315.

103. Gomez GA, McLachlan RW, Yap AS. Productive tension: force-sensing and homeostasis of cell-cel junctions. Trends Cell Biol. 2011;21(9):499-505.

104.Trepat X, et al. Physical forces during collective cell migration. Nat Phys. 2009;5(6):426-430.

105. Osawa M, Masuda M, Harada N, Lopes RB,
Fujiwara K. Tyrosine phosphorylation of platelet endothelial cell adhesion molecule-1 (PECAM-1, CD31) in mechanically stimulated vascular endothelial cells. Eur JCell Biol. 1997;72(3):229-237.

106.Tzima E, et al. A mechanosensory complex that mediates the endothelial cell response to fluid shear stress. Nature. 2005;437(7057):426-431.

107. Conway DE, Breckenridge MT, Hinde E, Gratton E, Chen CS, Schwartz MA. Fluid shear stress on endothelial cells modulates mechanical tension across VE-cadherin and PECAM-1. Curr Biol. 2013;23(11):1024-1030

108. Coon BG, et al. Intramembrane binding of VE-cadherin to VEGFR2 and VEGFR3 assembles the endothelial mechanosensory complex. JCell Biol. 2015;208(7):975-986.

109. Orr AW, Sanders JM, Bevard M, Coleman E, Sarembock IJ, Schwartz MA. The subendothelial extracellular matrix modulates NF-kappaB activation by flow: a potential role in atherosclerosis. JCell Biol. 2005;169(1):191-202.

110.Funk SD, Yurdagul A Jr., Green JM, Jhaveri KA, Schwartz MA, Orr AW. Matrix-specific protein kinase A signaling regulates p21-activated kinase activation by flow in endothelial cells. Circ Res. 2010;106(8):1394-1403.

111. Liu Y, et al. PTK787/ZK22258 attenuates stellate cell activation and hepatic fibrosis in vivo by inhibiting VEGF signaling. Lab Invest . 2009;89(2):209-221.

112. Gordon WR, et al. Mechanical allostery: evidence for a force requirement in the proteolytic activation of Notch. Dev Cell. 2015;33(6):729-736

113. Seo D, et al. A mechanogenetic toolkit for interrogating cell signaling in space and time. Cell. 2016;165(6):1507-1518.

114. Wang X, Ha T. Defining single molecular forces required to activate integrin and notch signaling. Science. 2013;340(6135):991-994.

115. Dees $C$, et al. Inhibition of Notch signaling prevents experimental fibrosis and induces regression of established fibrosis. Arthritis Rheum. 2011;63(5):1396-1404.

116. Xiao Z, et al. The Notch $\gamma$-secretase inhibitor ameliorates kidney fibrosis via inhibition of TGF- $\beta /$ Smad $2 / 3$ signaling pathway activation. Int J Biochem Cell Biol. 2014;55:65-71.

117. Hinz B, Pittet P, Smith-Clerc J, Chaponnier C, Meister JJ. Myofibroblast development is characterized by specific cell-cell adherens junctions. Mol Biol Cell. 2004;15(9):4310-4320.

118. Pittet P, Lee K, Kulik AJ, Meister JJ, Hinz B. Fibrogenic fibroblasts increase intercellular adhesion strength by reinforcing individual OB-cadherin bonds. J Cell Sci. 2008;121(pt 6):877-886.

119. Wu M, et al. Identification of cadherin 11 as a mediator of dermal fibrosis and possible role in systemic sclerosis. Arthritis Rheumatol. 2014;66(4):1010-1021.

120. Mendez MG, Janmey PA. Transcription factor regulation by mechanical stress. Int J Biochem Cell Biol. 2012;44(5):728-732.

121. Dupont $\mathrm{S}$, et al. Role of YAP/TAZ in mechanotransduction. Nature. 2011;474(7350):179-183.

122. Piccolo S, Dupont S, Cordenonsi M. The biology of YAP/TAZ: hippo signaling and beyond. Physiol Rev. 2014;94(4):1287-1312.

123. Attisano L, Wrana JL. Signal integration in 
TGF- $\beta$, WNT, and Hippo pathways. F1000Prime Rep. 2013;5:17.

124. Mannaerts I, et al. The Hippo pathway effector YAP controls mouse hepatic stellate cell activation. J Hepatol. 2015;63(3):679-688.

125. Piersma B, et al. YAP1 is a driver of myofibroblast differentiation in normal and diseased fibroblasts. Am J Pathol. 2015;185(12):3326-3337.

126.Szeto SG, et al. YAP/TAZ are mechanoregulators of TGF- $\beta$-Smad signaling and renal fibrogenesis. JAm Soc Nephrol. 2016;27(10):3117-3128.

127. Martin K, et al. PAK proteins and YAP-1 signalling downstream of integrin beta- 1 in myofibroblasts promote liver fibrosis. Nat Commun. 2016;7:12502.

128. Liu F, et al. Mechanosignaling through YAP and TAZ drives fibroblast activation and fibrosis. Am J Physiol Lung Cell Mol Physiol. 2015;308(4):L344-L357.

129. Noguchi S, et al. TAZ contributes to pulmonary fibrosis by activating profibrotic functions of lung fibroblasts. Sci Rep. 2017;7:42595.

130. Yu FX, et al. Regulation of the Hippo-YAP pathway by G-protein-coupled receptor signaling. Cell. 2012;150(4):780-791.

131. Knipe RS, Tager AM, Liao JK. The Rho kinases: critical mediators of multiple profibrotic processes and rational targets for new therapies for pulmonary fibrosis. Pharmacol Rev. 2015;67(1):103-117.

132. Zhou Y, et al. Inhibition of mechanosensitive signaling in myofibroblasts ameliorates experimental pulmonary fibrosis. J Clin Invest. 2013;123(3):1096-1108.

133. Olson EN, Nordheim A. Linking actin dynamics and gene transcription to drive cellular motile functions. Nat Rev Mol Cell Biol. 2010;11(5):353-365.

134. Posern G, Treisman R. Actin' together: serum response factor, its cofactors and the link to signal transduction. Trends Cell Biol. 2006;16(11):588-596.

135. Esnault C, et al. Rho-actin signaling to the MRTF coactivators dominates the immediate transcriptional response to serum in fibroblasts. Genes Dev. 2014;28(9):943-958.

136. Gualdrini F, Esnault C, Horswell S, Stewart A, Matthews N, Treisman R. SRF co-factors control the balance between cell proliferation and contractility. Mol Cell. 2016;64(6):1048-1061.

137. Haak AJ, et al. Targeting the myofibroblast genetic switch: inhibitors of myocardin-related transcription factor/serum response factor-regulated gene transcription prevent fibrosis in a murine model of skin injury. J Pharmacol Exp Ther. 2014;349(3):480-486.

138. Scharenberg MA, et al. TGF- $\beta$-induced differentiation into myofibroblasts involves specific regulation of two MKL1 isoforms. J Cell Sci. 2014;127(pt 5):1079-1091.

139. Sakai N, Chun J, Duffield JS, Wada T, Luster AD, Tager AM. LPA1-induced cytoskeleton reorganization drives fibrosis through CTGFdependent fibroblast proliferation. FASEB J. 2013;27(5):1830-1846.

140.Shiwen X, et al. A role of Myocardin Related Transcription Factor-A (MRTF-A) in scleroderma related fibrosis. PLoS One. 2015;10(5):e0126015.

141. Sisson TH, et al. Inhibition of myocardin-relat- ed transcription factor/serum response factor signaling decreases lung fibrosis and promotes mesenchymal cell apoptosis. Am J Pathol. 2015;185(4):969-986

142.Yu-Wai-Man C, et al. Local delivery of novel MRTF/SRF inhibitors prevents scar tissue formation in a preclinical model of fibrosis. Sci Rep. 2017;7(1):518.

143. Tian W, et al. Myocardin related transcription factor A programs epigenetic activation of hepatic stellate cells. J Hepatol. 2015;62(1):165-174.

144. Velasquez LS, et al. Activation of MRTF-Adependent gene expression with a small molecule promotes myofibroblast differentiation and wound healing. Proc Natl Acad Sci U S A. 2013;110(42):16850-16855.

145. Kim T, Hwang D, Lee D, Kim JH, Kim SY, Lim DS. MRTF potentiates TEAD-YAP transcriptional activity causing metastasis. $E M B O \mathrm{~J}$. 2017;36(4):520-535.

146.Speight P, Kofler M, Szászi K, Kapus A. Contextdependent switch in chemo/mechanotransduction via multilevel crosstalk among cytoskeleton-regulated MRTF and TAZ and TGF $\beta$-regulated Smad3. Nat Commun. 2016;7:11642.

147. Yu OM, Miyamoto S, Brown JH. Myocardinrelated transcription factor $\mathrm{A}$ and Yes-associated protein exert dual control in $G$ protein-coupled receptor- and RhoA-mediated transcriptional regulation and cell proliferation. Mol Cell Biol. 2016;36(1):39-49.

148. Jorgenson AJ, et al. TAZ activation drives fibroblast spheroid growth, expression of profibrotic paracrine signals, and context-dependent ECM gene expression. Am J Physiol Cell Physiol. 2017;312(3):C277-C285.

149. Cho S, Irianto J, Discher DE. Mechanosensing by the nucleus: from pathways to scaling relationships. J Cell Biol. 2017;216(2):305-315.

150. Padmakumar VC, et al. Enaptin, a giant actinbinding protein, is an element of the nuclear membrane and the actin cytoskeleton. Exp Cell Res. 2004;295(2):330-339.

151. Padmakumar VC, et al. The inner nuclear membrane protein Sun1 mediates the anchorage of Nesprin-2 to the nuclear envelope. J Cell Sci. 2005;118(pt 15):3419-3430.

152. Wilhelmsen K, et al. Nesprin-3, a novel outer nuclear membrane protein, associates with the cytoskeletal linker protein plectin. JCell Biol. 2005;171(5):799-810.

153. Poh YC, et al. Dynamic force-induced direct dissociation of protein complexes in a nuclear body in living cells. Nat Commun. 2012;3:866.

154.Cain NE, Starr DA. SUN proteins and nuclear envelope spacing. Nucleus. 2015;6(1):2-7.

155. Zhen YY, Libotte T, Munck M, Noegel AA, Korenbaum E. NUANCE, a giant protein connecting the nucleus and actin cytoskeleton. J Cell Sci. 2002;115(pt 15):3207-3222.

156. Alam SG, et al. The mammalian LINC complex regulates genome transcriptional responses to substrate rigidity. Sci Rep. 2016;6:38063.

157. Chang W, Antoku S, Östlund C, Worman HJ, Gundersen GG. Linker of nucleoskeleton and cytoskeleton (LINC) complex-mediated actin-dependent nuclear positioning orients centrosomes in migrating myoblasts. Nucleus.
2015;6(1):77-88.

158. Chang W, Worman HJ, Gundersen GG. Accessorizing and anchoring the LINC complex for multifunctionality. J Cell Biol. 2015;208(1):11-22.

159. Stewart RM, Zubek AE, Rosowski KA, Schreiner SM, Horsley V, King MC. Nuclear-cytoskeletal linkages facilitate cross talk between the nucleus and intercellular adhesions. J Cell Biol. 2015;209(3):403-418.

160.Andrés V, González JM. Role of A-type lamins in signaling, transcription, and chromatin organization. J Cell Biol. 2009;187(7):945-957.

161. Swift J, et al. Nuclear lamin-A scales with tissue stiffness and enhances matrix-directed differentiation. Science. 2013;341(6149):1240104.

162.Janmey PA, Wells RG, Assoian RK, McCulloch CA. From tissue mechanics to transcription factors. Differentiation. 2013;86(3):112-120.

163. Chen CY, et al. Accumulation of the inner nuclear envelope protein Sun1 is pathogenic in progeric and dystrophic laminopathies. Cell. 2012;149(3):565-577.

164.Lammerding J, et al. Lamin A/C deficiency causes defective nuclear mechanics and mechanotransduction. JClin Invest. 2004;113(3):370-378.

165. Chapman MA, et al. Disruption of both nesprin 1 and desmin results in nuclear anchorage defects and fibrosis in skeletal muscle. Hum Mol Genet. 2014;23(22):5879-5892.

166.Zuela N, Bar DZ, Gruenbaum Y. Lamins in development, tissue maintenance and stress. $E M B O$ Rep. 2012;13(12):1070-1078.

167. Van Berlo JH, et al. A-type lamins are essential for TGF-beta1 induced PP2A to dephosphorylate transcription factors. Hum Mol Genet. 2005;14(19):2839-2849.

168. Bourgeois B, et al. Inhibition of TGF- $\beta$ signaling at the nuclear envelope: characterization of interactions between MAN1, Smad2 and Smad3, and PPM1A. Sci Signal. 2013;6(280):ra49.

169.Lin F, Morrison JM, Wu W, Worman HJ. MAN1, an integral protein of the inner nuclear membrane, binds Smad 2 and Smad3 and antagonizes transforming growth factor-beta signaling. Hum Mol Genet. 2005;14(3):437-445.

170.Ho CY, Jaalouk DE, Vartiainen MK, Lammerding J. A/C and emerin regulate MKL1-SRF activity by modulating actin dynamics. Nature. 2013;497(7450):507-511.

171. Camozzi D, et al. Diverse lamin-dependent mechanisms interact to control chromatin dynamics. Focus on laminopathies. Nucleus. 2014;5(5):427-440.

172. Capell BC, Collins FS. Human laminopathies: nuclei gone genetically awry. Nat Rev Genet. 2006;7(12):940-952.

173. Peng $X$, et al. Inactivation of focal adhesion kinase in cardiomyocytes promotes eccentric cardiac hypertrophy and fibrosis in mice. J Clin Invest. 2006;116(1):217-227.

174. Meyer GA, Lieber RL. Skeletal muscle fibrosis develops in response to desmin deletion. $A m \mathrm{~J}$ Physiol Cell Physiol. 2012;302(11):C1609-C1620.

175. O'Reilly S. Epigenetics in fibrosis. Mol Aspects Med. 2017;54:89-102.

176. Tzouvelekis A, Kaminski N. Epigenetics in idiopathic pulmonary fibrosis. Biochem Cell Biol. 2015;93(2):159-170. 
177. Page A, Mann DA, Mann J. The mechanisms of HSC activation and epigenetic regulation of HSCs phenotypes. Curr Pathobiol Rep. 2014;2(4):163-170.

178. Bechtel W, et al. Methylation determines fibroblast activation and fibrogenesis in the kidney. Nat Med. 2010;16(5):544-550.

179. Lelièvre SA. Contributions of extracellular matrix signaling and tissue architecture to nuclear mechanisms and spatial organization of gene expression control. Biochim Biophys Acta. 2009;1790(9):925-935.

180. Downing TL, et al. Biophysical regulation of epigenetic state and cell reprogramming. Nat Mater 2013;12(12):1154-1162.

181. Tan Y, et al. Matrix softness regulates plasticity of tumour-repopulating cells via H3K9 demethylation and Sox 2 expression. Nat Commun. 2014;5:4619.

182. Le HQ, et al. Mechanical regulation of transcription controls Polycomb-mediated gene silencing during lineage commitment. Nat Cell Biol. 2016;18(8):864-875.

183. Crowder SW, Leonardo V, Whittaker T, Papathanasiou P, Stevens MM. Material cues as potent regulators of epigenetics and stem cell function. Cell Stem Cell. 2016;18(1):39-52.

184.Li Y, et al. Biophysical regulation of histone acetylation in mesenchymal stem cells. Biophys J. 2011;100(8):1902-1909.

185. Valenzuela-Fernández A, Cabrero JR, Serrador JM, Sánchez-Madrid F. HDAC6: a key regulator of cytoskeleton, cell migration and cell-cell inter- actions. Trends Cell Biol. 2008;18(6):291-297.

186.Fan Z, et al. MKL1 is an epigenetic modulator of TGF- $\beta$ induced fibrogenesis. Biochim Biophys Acta. 2015;1849(9):1219-1228.

187. Yu L, et al. MKL1 defines the H3K4Me3 landscape for NF- $\kappa$ B dependent inflammatory response. Sci Rep. 2017;7(1):191.

188. Heo SJ, Thorpe SD, Driscoll TP, Duncan RL, Lee DA, Mauck RL. Biophysical regulation of chromatin architecture instills a mechanical memory in mesenchymal stem cells. Sci Rep. 2015;5:16895.

189. Yang C, Tibbitt MW, Basta L, Anseth KS. Mechanical memory and dosing influence stem cell fate. Nat Mater. 2014;13(6):645-652.

190.Li CX, et al. MicroRNA-21 preserves the fibrotic mechanical memory of mesenchymal stem cells. Nat Mater. 2017;16(3):379-389.

191. Liu G, et al. miR-21 mediates fibrogenic activation of pulmonary fibroblasts and lung fibrosis. J Exp Med. 2010;207(8):1589-1597.

192. Chau BN, et al. MicroRNA-21 promotes fibrosi of the kidney by silencing metabolic pathways. Sci Transl Med. 2012;4(121):121ra18.

193. Arrowsmith CH, Bountra C, Fish PV, Lee K, Schapira M. Epigenetic protein families: a new frontier for drug discovery. Nat Rev Drug Discov. 2012;11(5):384-400.

194. Filippakopoulos P, Knapp S. Targeting bromodomains: epigenetic readers of lysine acetylation. Nat Rev Drug Discov. 2014;13(5):337-356.

195. Lyko F, Brown R. DNA methyltransferase inhibitors and the development of epigenetic cancer therapies. J Natl Cancer Inst. 2005;97(20):1498-1506.
196. Campbell RM, Tummino PJ. Cancer epigenetics drug discovery and development: the challenge of hitting the mark. JClin Invest. 2014;124(1):64-69.

197. Patsenker E, et al. Pharmacological inhibition of integrin alphavbeta3 aggravates experimental liver fibrosis and suppresses hepatic angiogenesis. Hepatology. 2009;50(5):1501-1511.

198.Wong VW, et al. Focal adhesion kinase links mechanical force to skin fibrosis via inflammatory signaling. Nat Med. 2011;18(1):148-152.

199.Lagares D, et al. Inhibition of focal adhesion kinase prevents experimental lung fibrosis and myofibroblast formation. Arthritis Rheum. 2012;64(5):1653-1664.

200.Rahaman SO, et al. TRPV4 mediates myofibroblast differentiation and pulmonary fibrosis in mice. J Clin Invest. 2014;124(12):5225-5238.

201. Davis J, Burr AR, Davis GF, Birnbaumer L, Molkentin JD. A TRPC6-dependent pathway for myofibroblast transdifferentiation and wound healing in vivo. Dev Cell. 2012;23(4):705-715.

202.Wu YL, et al. Inhibition of TRPC6 channels ameliorates renal fibrosis and contributes to renal protection by soluble klotho. Kidney Int. 2017;91(4):830-841.

203.Saliba Y, et al. Evidence of a role for fibroblast transient receptor potential canonical $3 \mathrm{Ca}^{2+}$ channel in renal fibrosis. J Am Soc Nephrol. 2015;26(8):1855-1876

204.Dekker RJ, et al. Prolonged fluid shear stress induces a distinct set of endothelial cell genes, most specifically lung Krüppel-like factor (KLF2). Blood. 2002;100(5):1689-1698 